\title{
Avaliação de Desempenho Paralelo de Montadores de DNA Velvet e SOAPdenovo2
}

\author{
Evaldo Bezerra da Costa \\ Programa de Pos Graduação em Informatica, PPGI, UFRJ \\ 21941-590, Rio de Janeiro, RJ \\ E-mail: evaldo.costa@ppgi.ufrj.br \\ Gabriel P. Silva Marcello Goulart Teixeira \\ Departamento de Ciência da Computação, DCC, UFRJ \\ 21941-590, Rio de Janeiro, RJ \\ E-mail: \{gabriel, marcellogt\}@dcc.ufrj.br
}

\begin{abstract}
RESUMO
Em bioinformática, existem vários programas disponíveis para montagem de sequência de DNA [1]. Isso geralmente é uma tarefa muito demorada, uma vez que essas sequências de DNA podem ser muito longas e complexas [2]. Assim, uma das principais preocupações com os montadores de DNA é o seu funcionamento e desempenho em sistemas paralelos, de tal maneira que a montagem possa ser realizada em um período de tempo razoável. Neste trabalho, avaliamos o desempenho paralelo dos montadores Velvet e SOAPdenovo2.

Velvet [3] e SOAPdenovo2 [4] são os dois programas de montagem NGS (Sequenciamento de Nova Geração) desenvolvidos usando o método de grafo de De Bruijn e com suporte a computação paralela de multithreaded.

Os testes foram realizados em um servidor com dois processadores Intel Xeon E5-2650 (2,00 GHz, 8 núcleos cada, $20 \mathrm{MB}$ de cache), com 64 GB de memória. Ambos os montadores, Velvet e SOAPdenovo2, foram compilados usando o Intel C++ Compiler Suite XE 13.1 Update 2 para prover um melhor desempenho.

Os dados utilizados para realizar os testes foram fornecidos pelo Instituto de Biologia da UFRJ e foram armazenados em um disco SSD (unidade de estado sólido) local de alta velocidade. O sistema operacional utilizado foi a distribuição Linux CentOS de 64 bits versão 6.3. Os arquivos de dados foram separados em quatro grupos, chamados muriqui8, muriqui9, muriqui10 e muriqui12 conforme apresentado na Tabela I.
\end{abstract}

\begin{tabular}{|c|c|c|c|}
\hline \multicolumn{4}{|c|}{ Conjunto de dados } \\
\hline muriqui8 & muriqui9 & muriqui10 & muriqui12 \\
\hline 1.7 GB & $6.24 \mathrm{~GB}$ & $16.6 \mathrm{~GB}$ & $10.8 \mathrm{~GB}$ \\
\hline
\end{tabular}

Tabela I. Tamanho dos conjuntos de dados

Para os resultados apresentados foram realizadas três séries de testes e calculado o tempo médio de execução dos montadores Velvet e SOAPdenovo2. A quantidade de threads usadas foi variada para determinar o speedup de cada montador.

Na Figura 1 é visto que o desempenho Velvet usando conjunto de dados muriqui9 foi melhor. O SOAPdenovo2 obteve um melhor desempenho utilizando o conjunto de dados muriqui10 como apresentado na Figura 2. Os resultados obtidos com o SOAPdenovo2 foram superiores ao Velvet, principalmente em função das melhorias que foram implementadas na versão atual. 


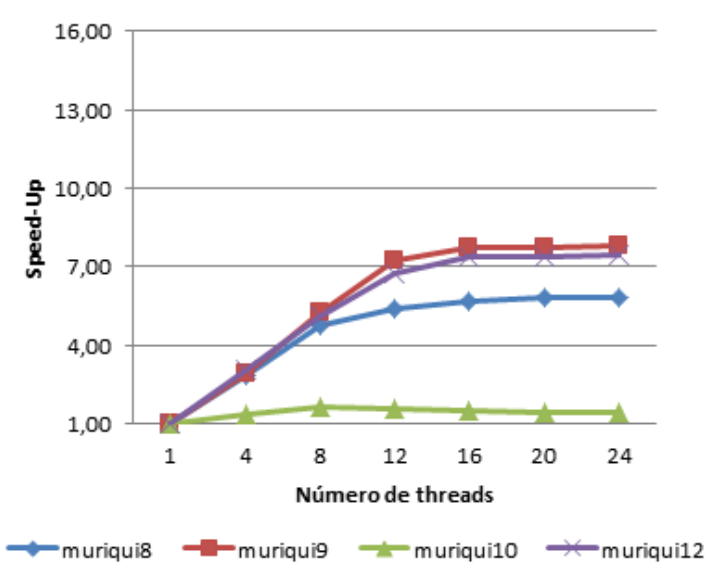

Figura 1: Speed up Velvet

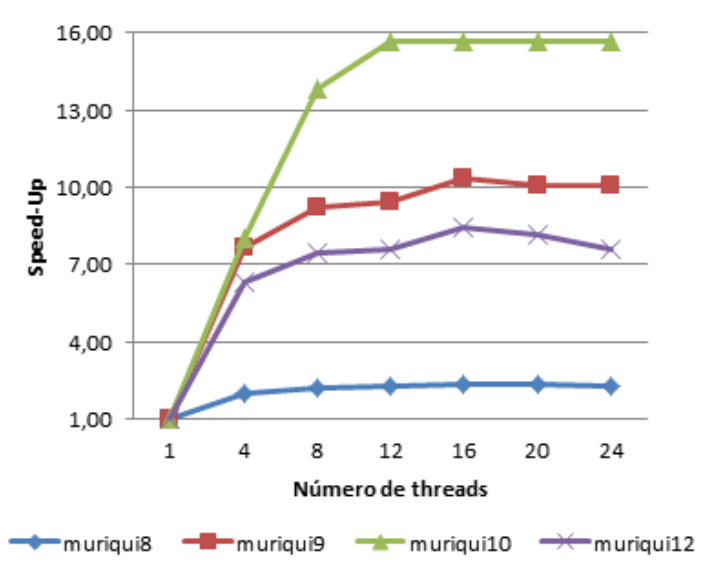

Figura 2: Speed up SOAPdenovo2

O tamanho da sequência a ser montada está relacionada diretamente com o desempenho dos montadores. Embora ambos os montadores utilizassem multithreads em seu processo de execução, o Velvet não utiliza todas as threads especificadas para execução em seu processo, principalmente durante o passo de leitura das sequências. O SOAPdenovo2 utiliza todas as threads especificadas em todos os passos.

Palavras-chave: Montador DNA, SOAPdenovo2, Velvet, Avaliação de desempenho

\section{Referências}

[1] Costa, Gustavo Gilson Lacerda. O Laboratório Central de Tecnologias de Alto Desempenho em Ciências da Vida (LaCTAD). Introdução à montagem de genomas, 2013.

[2] Ruiqiang Li, Hongmei Zhu, et al. De novo assembly of human genomes with massively parallel short read sequencing. Genome Res, 20(2):265-72, February 2010.

[3] Zerbino, Daniel and Ewan Birney. Velvet: algorithms for de novo short read assembly using de bruijn graphs. Genome Research, 18(5):821-829, 2008.

[4] Luo R, Liu B, et al. Software and supporting material for "SOAPdenovo2: an empirically improved memory efficient short read de novo assembly". 2012. 3. 